\title{
APRENDENDO COM A AMAZÔNIA
}

\author{
Leonardo Ferreira Peixoto
}

Resumo

Este artigo é forjado em meio a narrativas (auto)biográficas de formação em contexto amazônico, relativizando as perspectivas Norte-Sul no / do Brasil, a partir das epistemologias do Sul de Boaventura de Sousa Santos. O uso do gerúndio do verbo aprender no título é proposital, uma vez que marca a trajetória de um professor que se reconhece em contínuo e constante processo de formação e transformação. O texto parte, inicialmente, da mudança geográfica, quando o autor migra da região Sudeste do Brasil para a região Norte, especificamente do estado do Rio de Janeiro (RJ) para o estado do Amazonas (AM), ressaltando algumas aprendizagens que decorrem desta mudança. As narrativas estão focadas, principalmente, nas transformações politicasepistemológicas a partir das aprendizagens com os indígenas da região do Alto Solimões (AM), na tríplice fronteira amazônica entre o Brasil, a Colômbia e o Peru. O artigo conclui com uma reflexão sobre como não indígenas podemos aprender a ser parente.

Palavras-chave: epistemologias do Sul; Amazônia; educação indígena.

\section{LEARNING WITH THE AMAZON}

\section{Abstract}

This article is forged in the midst of (auto)biographical narratives of formation in the Amazon context, relativizing the North-South perspectives in / from Brazil, based on the epistemologies of the South of Boaventura de Sousa Santos. The use of the gerund of the verb to learn in the title is purposeful, since it marks the trajectory of a teacher who recognizes himself in a continuous and constant process of formation and transformation. The text starts from the geographical change, where the author migrates from the Southeast region of Brazil to the North region, specifically from the state of Rio de Janeiro (RJ) to the state of Amazonas (AM), highlighting some learnings that result from this change. The narratives are mainly focused on politicalepistemological transformations based on learning from the indigenous peoples of the Alto Solimões (AM) region, on the triple Amazonian border between Brazil, Colombia and Peru. The article concludes with a reflection on how non-indigenous people can learn to be parente.

Keywords: epistemologies of the South; Amazon; indigenous education.

\section{APRENDIENDO CON LA AMAZONÍA}

Resumen

Este artículo está forjado en medio de narrativas (auto)biográficas de formación en el contexto amazónico, relativizando las perspectivas Norte-Sur en / desde Brasil, basadas en las epistemologías del Sur de Boaventura de Sousa Santos. El uso del gerundio del verbo para aprender en el título tiene un propósito, ya que marca la trayectoria de un maestro que se reconoce a sí mismo en un proceso continuo y constante de formación y transformación. El texto comienza con el cambio geográfico, donde el autor migra desde la región Sureste de Brasil hacia la región Norte, específicamente desde el estado de Río de Janeiro (RJ) hasta el estado de Amazonas (AM), destacando algunos aprendizajes que resultan de este cambio. Las narraciones se centran, principalmente, en transformaciones políticoepistemológicas basadas en el aprendizaje de los pueblos indígenas de la región de Alto Solimões (AM), en la triple frontera amazónica entre Brasil, Colombia y Perú. El artículo concluye con una reflexión sobre cómo las personas no indígenas pueden ser parente.

Palabras clave: epistemologías del Sur; Amazonía; educación indígena. 


\section{MUDANDO DE RIO}

Acordei cedo e desci as escadas do prédio que fica localizado na Avenida da Amizade, principal via de Tabatinga (AM). Como de costume, pedi uma água de coco na lanchonete ao lado e fiquei a observar a Avenida e seu fluxo de motos, carros e pessoas. Às sete horas da manhã já se percebia um número considerável de motos a circular. Acho que a moto é o principal meio de transporte da cidade. A Avenida da Amizade é uma via com duas pistas separadas por um canteiro que se estende da Vila Militar, próxima ao aeroporto da cidade, até a fronteira com a Colômbia. Essa é a principal via terrestre do município de Tabatinga. Uma grande linha reta com aproximadamente dois quilômetros de extensão. $\mathrm{Na}$ fronteira com a Colômbia, ela muda de nome e passa a ser chamada de Avenida Internacional.

Sentado e bebendo a água de coco, comecei a pensar em caminhos, em trajetórias e fiquei pensando em como essa Avenida foi construída na cidade. Moro em Tabatinga desde outubro de 2012, quando me mudei para a cidade, depois de aprovado em concurso público e me tornei professor da Universidade do Estado do Amazonas ${ }^{1}$, e confesso que são poucas as transformações perceptíveis na estrutura do centro da cidade. Elas existem, mas nada se compara, por exemplo, às transformações provocadas pelo rio Solimões no bairro conhecido como Comara. Decidi pegar um mototáxi e seguir até o referido bairro. À beira do Rio Solimões, é possível perceber claramente as fortes transformações que suas margens sofreram ao longo desses anos.

"O rio não é como uma estrada", penso. A estrada é um caminho construído que se impõe sobre o meio; um caminho quase estático, que não se move, são as coisas que se movem sobre ela. O rio não. O rio é um caminho que se faz em constante movimento, e o rio Solimões, ou rio Amazonas, já que é o mesmo rio que tem muitos nomes, dependendo de qual trecho dele se fala, é um caminho que se se transforma rapidamente e a todo momento, provocando mudanças avassaladoras nas margens, por conta da força de suas águas. O rio rejeita o ser, ele é puro tornarse, é puro fluir. Essa minha percepção é afetada pela leitura de alguns textos de Nietzsche. Ressalto a citação de um artigo do Professor Jelson Roberto de Oliveira, no qual ele afirma que "Por 'rejeitar o ser' e conhecer apenas o 'tornar-se e o fluir"', Heráclito representa, para Nietzsche, a denúncia de que a existência, interpretada à la Platão, repousa eternamente de forma estéril em erros fixos: "Eis a intuição de Heráclito: não existe nada do qual se possa dizer 'é"' (OLIVEIRA, J. R., 2010).

Eu não era capaz de imaginar este cenário, antes de estar aqui. Nunca tinha visto rios tão grandiosos, com margens tão distantes umas das outras, sobretudo na época de cheia. Isso era distante demais para mim, longe demais da minha experiência e das realidades nas quais vivia até então, e, portanto, incaptável pelo meu imaginário. Descobri que os rios que eu conhecia do "meu Rio" (de Janeiro) sequer ganhariam status de rio na região amazônica, seriam boa parte deles considerados igarapés, que são braços de rios pequenos demais para gozar do status de rio. Descobri também que, normalmente, não é uma única chuva que faz os rios transbordarem e causarem caos à cidade, como era no "meu Rio". São necessários meses de muita chuva e meses de pouca chuva para alterar essas margens e cursos. É esse fluxo chuva / seca que faz os rios estarem nas épocas de cheias ou vazantes, como dizem aqui.

Como entrar no rio e não se molhar? Para mim, foi inevitável "mergulhar" na floresta amazônica e não ser completamente impregnado por ela. Tenho hoje a Amazônia tatuada em meu peito; a Amazônia e o Rio de Janeiro, um pouco de como acho que venho me reinventando ao longo dos últimos anos de vida. Essa Amazônia hoje tão agredida por governos que a querem

\footnotetext{
${ }^{1}$ Escrevi esta reflexão inicial em maio de 2018.
} 
alimentando o grande capital, que não se importam com ela, com sua riqueza, seus povos e culturas, e nem mesmo com a necessidade planetária de sua preservação. Este é um mundo que venho aprendendo a conhecer, a sentir e a me tornar parte dele.

Viver em Tabatinga mudou meu modo de sentir o mundo, me fazendo percebê-lo de outras maneiras, com outros sons, outros cheiros, outros alimentos e outras temporalidades, outras epistemes e modos de compreender e estar nele. A primeira grande mudança se deu na maneira como percebo e compreendo a presença dos indígenas em nosso país, que até então eram invisibilizados para mim. O imaginário "do índio", que foi reiterado ao longo de minha vida, não corresponde ao que passei a vivenciar em meus cotidianos desde 2012. Aquilo que aprendemos sobre os indígenas do nosso país em nossos cotidianos hegemônicos da ex-capital da República, dentrofora (ALVES, 2010) das escolas é extremamente reducionista e beirando ao desrespeito. Um bom exemplo dessa visão deturpada e precária da presença indígena no nosso país nos é trazido por Oliveira (2002), quando narra um diálogo com seu filho Tiago, então com oito anos de idade e o interpreta.

Mãe, ainda existem índios no Brasil?

É claro, meu filho! Muitos vivem nas cidades e são pessoas como você. Usam roupas comuns, almoçam, jantam, vão ao banheiro e assistem televisão.

Quer dizer que há índios que viraram ser humano, mãe?

A situação em questão evidencia uma aprendizagem do preconceito racial e cultural, tecida na vivência cotidiana e nos contatos com os valores culturais dominantes, dentro e fora da escola. Tiago já percebeu a lógica da estratificação social brasileira, e já "sabe" que "os índios eram povos 'selvagens e primitivos' e desapareceram após o descobrimento e a civilização do Brasil”. A indissociabilidade entre o político e o epistemológico na reflexão curricular. (OLIVEIRA, 2002, p. 40).

Posso dizer que, de alguma forma, meu imaginário sobre os povos indígenas se aproximava do de Tiago, mesmo tendo recebido formação muito diferente da dele, um menino branco, de classe média, estudando em uma escola conhecida pela excelência de seu ensino. A distância epistêmica compartilhada entre mim e Tiago acompanha a imensa distância geográfica que separa um município do outro. São 3.550 quilômetros de distância ${ }^{2}$, aproximadamente 12 horas de voo com conexões e o fuso horário com duas horas a menos do horário de Brasília.

\footnotetext{
2 Para termos uma melhor ideia do que essa distância significa, comparamos com a Europa. A distância de seu extremo Leste, a cidade de Istambul até La Coruña, cidade do extremo Leste da Espanha, é de 3.800 quilômetros.
} 
Figura 1: Mapa do Brasil com a localização do Rio de Janeiro e Tabatinga

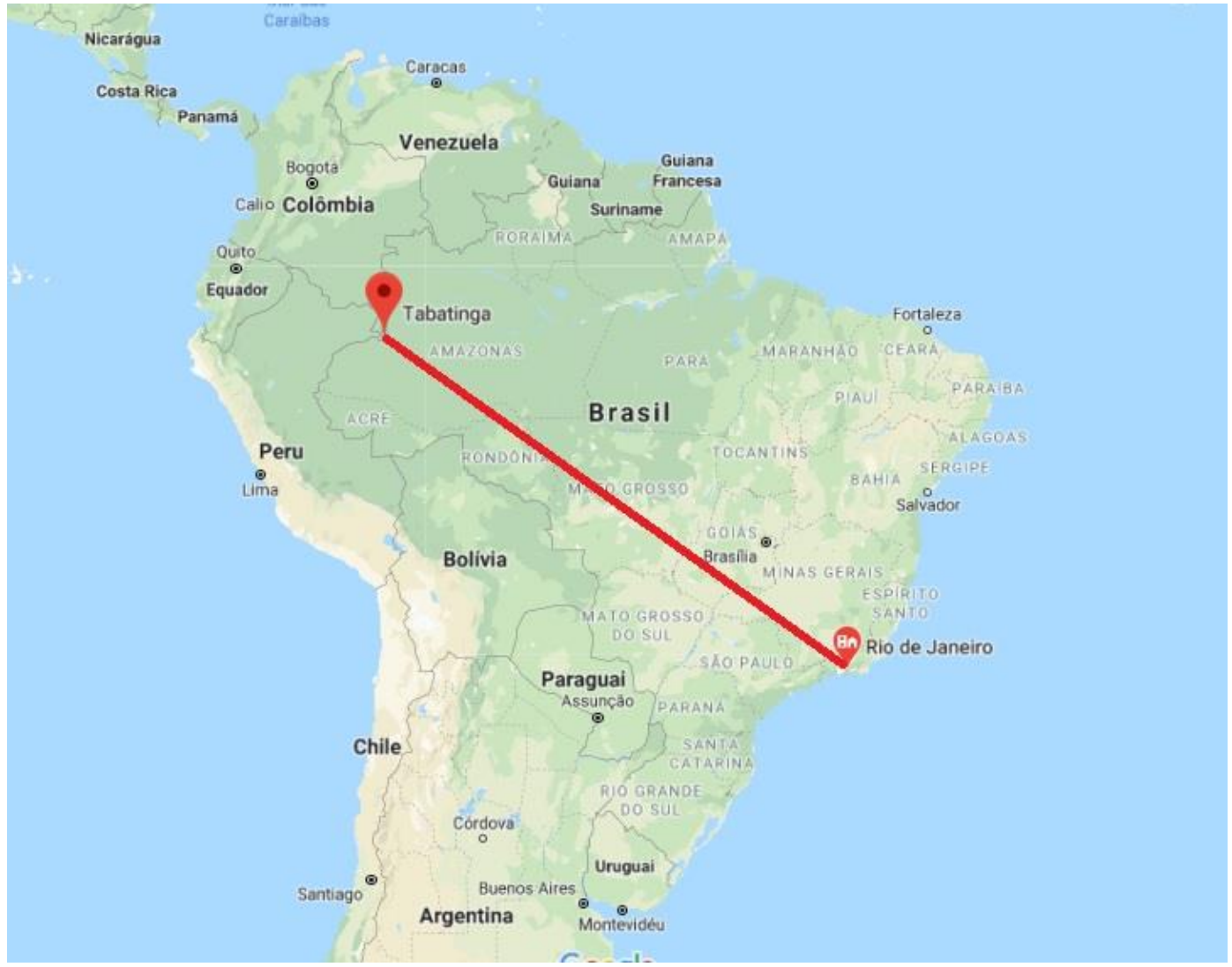

Fonte: Google. Acesso em 19 abr. 2020 às 16h47min

Mas o Rio de Janeiro também tem suas distâncias, físicas, sociais e epistêmicas. Sou natural de Belford Roxo, município da Baixada Fluminense no estado do Rio de Janeiro, região que tem a fama de ser muito violenta e pobre, em relação à capital do estado, apesar de ser bem próxima fisicamente. A região metropolitana do Rio de Janeiro, ou Grande Rio, é marcada por imensos contrastes sociais. Em 2012, me mudei para Tabatinga (AM), município que, como mostramos no mapa acima, fica localizado na tríplice fronteira amazônica entre Brasil, Colômbia e Peru.

O município pertence ao estado brasileiro do Amazonas e está na chamada microrregião do Alto Solimões, na mesorregião Sudoeste amazonense, conforme divisão do estado, que é feita em microrregiões que se agrupam em mesorregiões, conforme mapa a seguir: 
Figura 2: Amazonas - Microrregiões

\section{ESTADO DO AMAZONAS: MICRORREGIÖES}

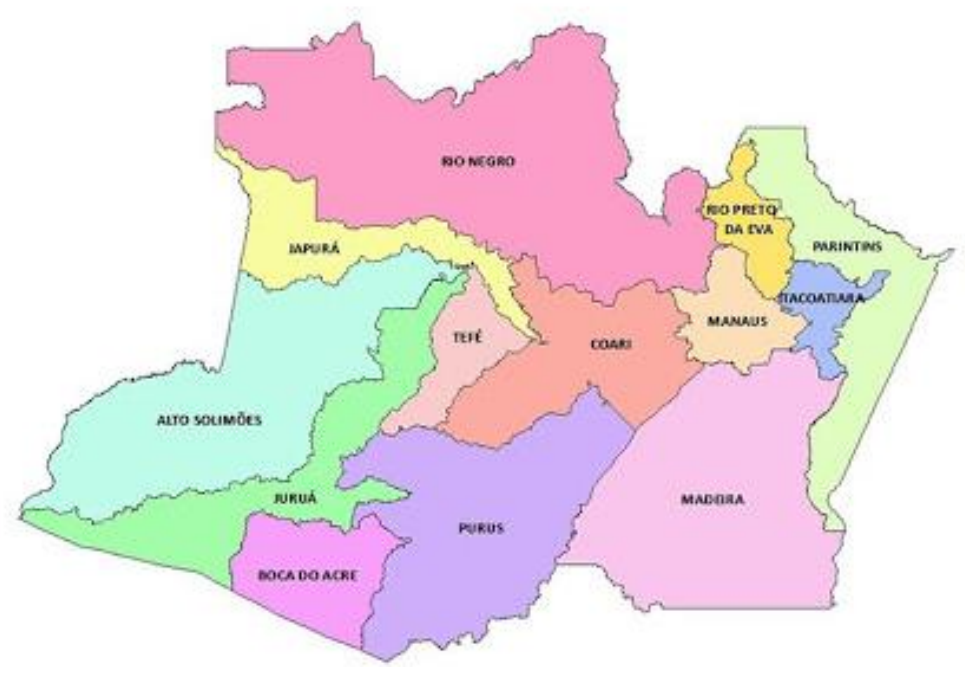

Fonte: Wikipédia. Acesso em 19 abr. 2020 às 16h48min

Os mapas buscam mostrar um pouco do que é Tabatinga por meio de dados geográficos e geopolíticos. Embora não bastem para compreendermos o grau de mudança que significa sair de Belford Roxo para Tabatinga, e tampouco permitam compreender as dimensões culturais e políticas mais amplas que a mudança traz, esses dados nos ajudam, certamente, a nos localizarmos geográfica, política, cultural e epistemologicamente no desafio e nas transformações que advieram da mudança.

\section{PERCEBENDO A PRESENÇA INDÍGENA}

Desde que me mudei, passei a conviver cotidianamente com estudantes e professores indígenas. E, mais do que apenas conviver, passei a me dar conta da existência e da presença dos indígenas em nossos cotidianos, não apenas na região Norte do país. Foi preciso ir para a Amazônia, espaçotempo ${ }^{3}$ que no imaginário brasileiro é entendido como "lugar de índio", para perceber que os indígenas estão presentes em todas as regiões do país, como mostra o mapa abaixo, elaborado pelo Instituto Brasileiro de Geografia e Estatística, com os dados do Censo Indígena de 2010.

\footnotetext{
${ }^{3}$ É tradição comum aos pesquisadores afiliados à linha de pesquisa nosdoscom os cotidianos escolares, criar neologismos como este quando não encontramos em nossa língua uma única palavra que dê conta do que pretendemos dizer.
} 
Figura 3: Mapa da população indígena no Brasil

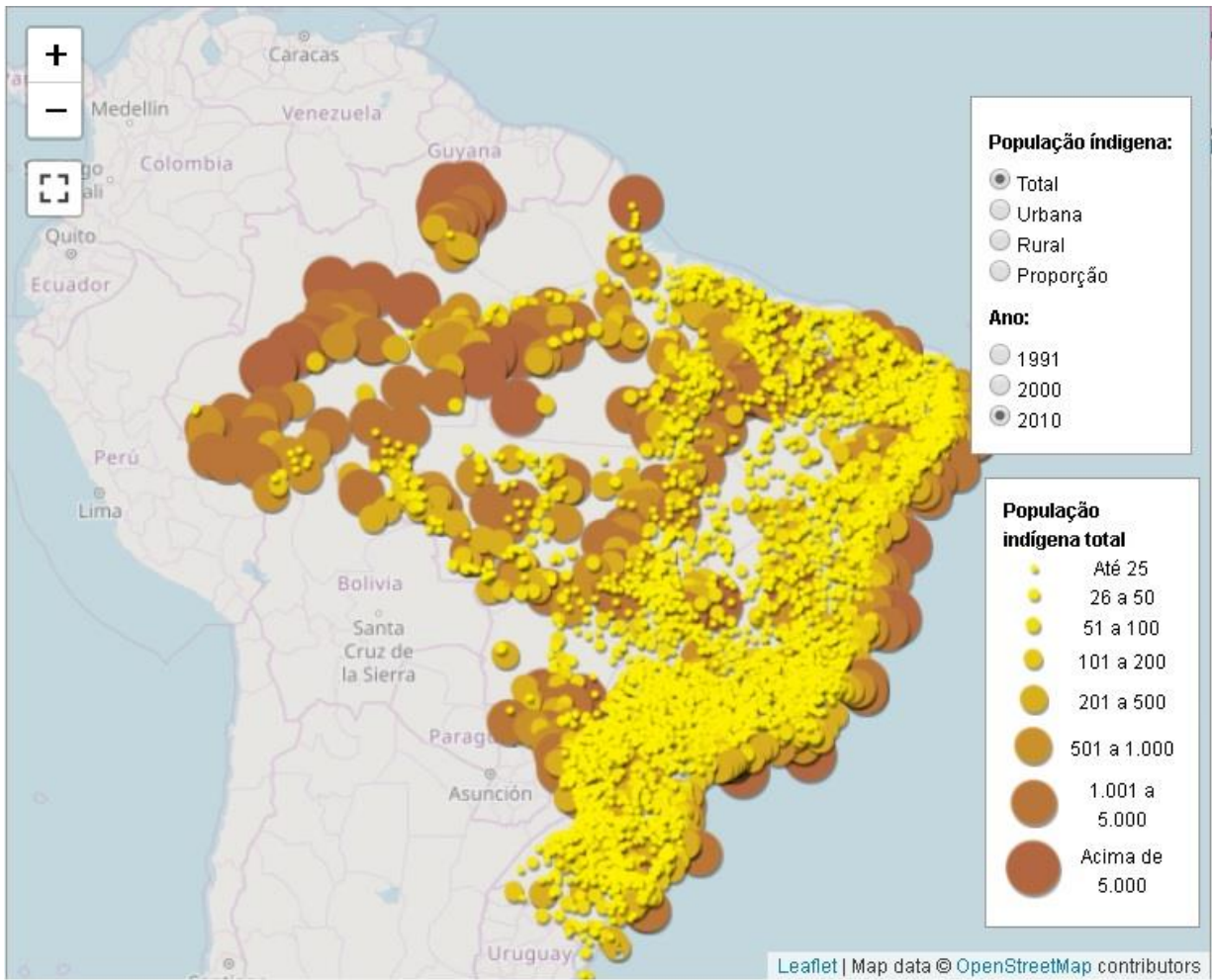

Fonte: IBGE - Censo Demográfico de 2010. Acesso em 19 abr. 2020 às 16h49min

Uma amiga indígena da etnia baniwa, que mora no Rio de Janeiro por conta do seu curso de pós-graduação, publicou a seguinte postagem em uma rede social:

\section{Figura 4: Postagem Fran Fontes}

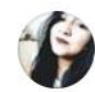

Fran Fontes está ถి se sentindo engraçada.

22 de outubro de $2018 \cdot$

Eu sentada no ônibus, chega uma senhora e senta ao meu lado;

Ela: vc é chinês brasileira né?

Eu: (risos)

Ela: sua cor e seus olhos são lindos;

Eu: ????

Ela: vc fala bem português né? Isso é incrível.;

Eu: Não muito, mas eu tento;

Ela: Na China é ruim de trabalhar né?

Eu: ?????

Ela: Mas nós amamos chineses, São melhores amigos dos brasileiros.

Eu: ????? Ela não me dava oportunidade de responder (risos);

Ela: Vc é muito simpática!

Cada coisa q me acontece nessa vida, sai do ônibus rindo $\because * \bullet$

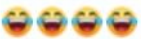

Além de peruana, chilena, agora sou chinesa $\Theta \Theta C$.

(1):3 94

22 comentários

Fonte: Facebook. Acesso em 19 abr. 2020 às 16h49min 
A invisibilidade que os indígenas sofrem ao Sul do Brasil é tamanha que para alguns é mais crível, ou próximo, pensar em peruanos, chilenos, ou até mesmo chineses do que perceber e reconhecer a presença e a existência de indígenas nas cidades e nos nossos cotidianos. Tiago não estava tão longe do imaginário de boa parte dos nossos adultos quando se perguntou, e à sua mãe, se ainda havia índios no Brasil ${ }^{4}$. E essa invisibilidade atinge não só os sujeitos indígenas, mas suas culturas, línguas, expressões e compreensões de mundo. É uma invisibilidade ativamente produzida (SANTOS, 1995) pelo colonizador que produz exclusão social, política, econômica e desqualifica a cultura, entendida como "coisa de selvagens" ou "folclore".

Segundo o Censo Demográfico de $2010^{5}, 80,5 \%$ dos municípios brasileiros possuem população indígena residente em zona rural ou urbana. Esse número vem aumentando progressivamente. No Censo Demográfico de $2000^{6}$, o percentual de municípios com indígenas residentes era de 63,5\% e no Censo Demográfico de $1991^{7}$ era de 34,5\%. O fenômeno marca uma mudança significativa na relação entre populações indígenas e não indígenas. Podemos pensar que a invisibilidade vem se reduzindo, em virtude das muitas mudanças e conquistas recentes, relacionadas à democratização do país, desde o fim da ditadura militar e a ações de movimentos sociais indígenas e indigenistas, e, em alguns casos, de governos locais.

\section{PROBLEMA DE PESQUISA E CAMINHOS TEÓRICOSPOLÍTICOSEPISTEMOLÓGICOS}

A mudança para o Amazonas me proporcionou, ainda, a oportunidade de atuar em cursos voltados especificamente para a formação de professores indígenas, o que me trouxe conhecimentos sobre suas formações "fora" dos espaços formais, suas culturas, pertencimentos e pluralidade. Em conversas informais, muitos professores indígenas narravam que começaram a lecionar nas escolas das comunidades antes de concluírem um curso de formação de professores; às vezes, antes mesmo de concluírem a educação básica. Conversando e pesquisando assistematicamente a questão, percebi que isso depende da localização da comunidade, da distância entre ela e a cidade-sede, da dificuldade ou não de acesso às escolas, da disponibilidade das secretarias de educação em lotar professores em determinadas áreas e de outros fatores que são característicos dos municípios do interior do Amazonas.

Comecei a ouvir falar na existência de "professores-leigos", uma categoria até então desconhecida por mim. Encontrei alguns locais com "professores-leigos" com mais de dez anos de prática docente. Fui-me surpreendendo com o tempo de exercício de alguns, que chegava a ser superior a trinta anos de atuação. E a questão despertou meu interesse.

Foi então que comecei a me interessar por essas trajetórias de formação de professores. $\mathrm{E}$ a indagar: quais são as trajetórias de formação desses professores indígenas? Como a noção de professor-leigo dialoga com os tantos saberes desses docentes e suas trajetórias de atuação tão

\footnotetext{
${ }^{4}$ Recentemente coube ao atual Presidente da República referir-se aos indígenas como "quase humanos" em uma declaração que, por um lado, envergonha a nação, e, infelizmente, por outro, permite às elites continuarem negando, a esses povos, a igualdade cidadã à qual têm direito.

${ }^{5}$ Fonte: IBGE. Disponível em: https://indigenas.ibge.gov.br/graficos-e-tabelas-2.html. Acesso em 18 jan. 2018.

${ }^{6}$ Fonte: Idem.

${ }^{7}$ Fonte: Ibidem.
} 
longas? Quais os sentidos das escolas indígenas para esses professores e que conhecimentos são valorizados em suas políticaspráticas ${ }^{8}$ cotidianas?

Foram essas questões iniciais que inspiraram minhas primeiras conversas com professores indígenas. Meu interesse inicial era conversar com aqueles que tivessem atuado como professores antes mesmo de fazer qualquer curso de formação inicial, os chamados "professores-leigos". Meu objetivo principal era entender como esses professores compreendem seus papéis sociais, qual a importância que dão para as escolas e os usos (CERTEAU, 2012) que dela fazem em suas comunidades e como foram se construindo, tornando-se professores por meio da prática cotidiana, antes mesmo de fazer algum curso de formação inicial.

Comecei a pensar sobre que professores indígenas deveriam ser esses com os quais trabalharia mais amiúde ao longo da pesquisa. Se eu deveria focar em uma determinada etnia ou se isso não seria uma questão relevante. Fui seguindo os rumos sem definir a priori quem seriam esses interlocutores. Ao longo das vivências com esses professores em formação, aprendendo inclusive o quanto já sabiam sobre a profissão, é que fui delineando com quem trabalharia e como o faria, método de trabalho comum nas pesquisas com os cotidianos, que já era uma opção teóricometodológica anterior ao início da pesquisa empírica.

Ou seja, do ponto de vista metodológico, essa pesquisa se desenvolve na linha dos estudos nosdoscom os cotidianos escolares. Para Oliveira (2011), pesquisar o cotidiano é realizar uma pesquisa "nos / dos / com os cotidianos". Uma pesquisa que surge "do cotidiano", de um pesquisador que está "no cotidiano" e que pretende romper com a lógica de hierarquização entre sujeito, pesquisador e objeto pesquisado, sendo então realizada não sobre o cotidiano, procurando explicálo, mas "com o cotidiano", entre sujeitos, procurando compreender a realidade pesquisada. Nesse sentido, a produção de conhecimento se situa na compreensão da tessitura dos conhecimentos em rede, que rompe com a ideia de fronteira, e de hierarquia, entre a produção acadêmica formal e a produção de conhecimentos nos cotidianos.

Michel de Certeau (20120 tem sido um autor comum a todos nós, pesquisadores filiados aos estudos nosdoscom os cotidianos. Destaco a perspicácia de Certeau (2012) para perceber a existência de resistências e criações produzidas em espaçostempos de aparente padronização, uniformização e homogeneização. Em nosso grupo de pesquisa, temos chamado esse movimento de resistências criativas, buscando entender de que modo o que Certeau identifica em sua pesquisa e esclarece no seu livro vem estando presente na realidade brasileira, desde o início da crise política em 2013 e seus desdobramentos após as eleições de 2014. Entendemos que, desde 2015, o Brasil vem se afundando em uma série crise política, fomentada e reiterada por grupos midiáticos e políticos hegemônicos. Essa crise teve seu ápice em agosto de 2016, quando, através de uma manobra orquestrada por esses setores políticos, jurídicos e midiáticos se concretizou o impeachment da presidenta eleita Dilma Rousseff. No estado do Rio de Janeiro, assistimos entre o final de 2015 e o ano de 2018, a um governo estadual minando e descuidando dos setores públicos e, especialmente, da Universidade do Estado do Rio de Janeiro (UERJ). Resistindo a isso, surgiram então diversos movimentos em defesa da UERJ que passaram a ser identificados nas redes sociais como: \#UERJResiste, revisitado por alguns como \#UERJexiste. Além disso, em diversas manifestações no período, bradamos esse "lema" em defesa da UERJ: “UERJ resiste!" Foi então que a professora Nilda Alves passou a chamar a atenção de todos, complementando o lema e formulando a noção: "UERJ resiste e cria". Com isso, Nilda Alves fez com que se percebesse que

\footnotetext{
${ }^{8}$ Entendemos, com Oliveira (2012), que não é possível compreender as práticas docentes desvinculadas de uma ação política. Estou considerando política como um conjunto de ações intencionais praticadaspensadas pelos atores sociais e que podem ocorrer em diversos âmbitos e níveis de relação.
} 
diferentes sujeitos resistem de múltiplas formas e que criam novidades e ações dentro de determinadas condições de possibilidade, para além daquilo que fazem como mera resistência ao poder instituído. Assim, a partir dessa noção, formulei outra, a de resistências criativas. Inês Barbosa de Oliveira também teve o mesmo insight. Estamos enredados! A noção de resistências criativas pretende contemplar o que é produzido / criado a partir de usos próprios e astuciosos de normas instituídas e de táticas cotidianas dos praticantespensantes da vida cotidiana, aproveitando-se de ocasiões que surgem para "lances" criativos dentro das regras de um jogo não definidas por eles. Para Certeau (2012, p. 100-101):

A tática é movimento "dentro do campo de ação do inimigo" como dizia von Büllow, e no espaço por ele controlado. Ela não tem, portanto, a possibilidade de dar a si mesma um projeto global nem de totalizar o adversário num espaço distinto, visível e objetivável. Ela opera golpe por golpe, lance por lance. Aproveita as ocasiões e delas depende, sem base para estocar benefícios, aumentar a propriedade e prever saídas. O que ela ganha não se conserva. Este não-lugar lhe permite sem dúvida mobilidade, mas numa docilidade aos azares do tempo, para captar no voo as possibilidades oferecidas por um instante. Tem que utilizar, vigilante, as falhas que as conjunturas particulares vão abrindo na vigilância do poder proprietário. Aí vai caçar. Cria ali surpresas. Consegue estar onde ninguém espera. É astúcia.

A noção e a argumentação certeaunianas contribuíram enormemente para a formulação dos movimentos considerados por Nilda Alves (2001, 2008a, 2008b) ${ }^{9}$ como necessários e característicos das pesquisas nosdoscom os cotidianos. Usando a metáfora do mergulho com todos os sentidos nos cotidianos como o primeiro movimento necessário a esse tipo de pesquisa, em busca da superação do primado do olhar e do distanciamento sobre os demais sentidos e sobre a interação com os sujeitos pesquisados, a autora defende a ideia de que estar no cotidiano é não só possível para o desenvolvimento de pesquisas acadêmicas como necessário se quisermos compreender essa realidade em sua complexidade constitutiva. Foi nessa perspectiva que, em fevereiro de 2016, "mergulhei" como professor e pesquisador na disciplina de Didática Intercultural no curso de Pedagogia Intercultural Indígena da Universidade do Estado do Amazonas, localizado no município de São Paulo de Olivença. Distante a aproximadamente 120 quilômetros de Tabatinga, também às margens do rio Solimões, a viagem entre as duas cidades se faz, atualmente, somente de barco ou lancha. A viagem mais rápida, de lancha, dura cinco horas e meia.

O curso já finalizado contava com duas turmas, com 79 indígenas de três etnias (Ticuna, Kokama e Kambeba/Omágua ${ }^{10}$ ) matriculados $^{11}$. Lancei-me como docente e pesquisador nesse

\footnotetext{
${ }^{9}$ Estes movimentos foram revistos e modificados em artigo recente, publicado por Nilda Alves, Alessandra Nunes Caldas e Nívea Andrade no livro Estudos do cotidiano, currículo e formação docente: questões metodológicas, políticas e epistemológicas, organizado por Inês Barbosa de Oliveira, Leonardo Ferreira Peixoto e Maria Luiza Süssekind, editado pela Editora CRV em 2019. O artigo intitula-se: Os movimentos necessários às pesquisas com os cotidianos - após muitas "conversas" acerca deles.

${ }^{10}$ Kambeba e Omágua são duas formas de se referir ao mesmo povo. Segundo Eronilde, sua cacique, Kambeba é o nome dado pelos colonizadores e Omágua é como os indígenas originalmente se autodenominam, porém ainda existe uma força política no uso de Kambeba, por isso no diálogo com Eronilde manteremos o uso de Kambeba que é como se organiza o movimento do Alto Solimões. OKAS: Organização Geral do Povo Kambeba do Alto Solimões.

${ }^{11} \mathrm{O}$ curso em questão foi ofertado pela Universidade do Estado do Amazonas, exclusivamente para professores indígenas em exercício do magistério, mas que não tinham formação inicial na área. Existe também um curso ocorrendo no município de Atalaia do Norte, próximo a Tabatinga, mas que abrange a região do Vale do Javari. No curso de
} 
curso com todos os meus sentidos, em busca de professores indígenas que pudessem ser interlocutores dessa pesquisa. No período em que estive em São Paulo de Olivença (fev. 2016), encontrei os três interlocutores nos quais decidi apostar: 1) Ondino ${ }^{12}$, professor indígena da etnia Ticuna; 2) Prudêncio, professor indígena da etnia Kokama e 3) Eronilde, professora indígena da etnia Kambeba.

Ondino estava matriculado no curso de Pedagogia Intercultural de São Paulo de Olivença e foi meu aluno na disciplina de Didática Intercultural (fev. 2016) e na disciplina Organização Curricular para as escolas indígenas (jan. 2017). Ondino é Ticuna e é professor da rede de São Paulo de Olivença desde 1983. Ele começou a dar aulas em sua comunidade quando tinha concluído a antiga $4^{a}$ série primária, aos 19 anos. Nas conversas realizadas, Ondino revelou inúmeras políticaspráticas que envolvem a educação de indígenas e a formação de indígenas Ticunas na região do Alto Solimões, além de narrar um pouco mais de sua trajetória como professor, mencionando inclusive uma viagem que fez para a Europa, para a Itália precisamente, para trocar conhecimentos com as escolas de ensino fundamental italianas.

Prudêncio é professor indígena da etnia Kokama. Conhecemo-nos em um Seminário de Pedagogia realizado com as turmas de São Paulo de Olivença, em fev. 2016. Prudêncio já tinha o curso superior, fez uma licenciatura destinada a indígenas promovida pela UEA em São Paulo de Olivença. Vive na comunidade Monte Santo, que fica bem próxima à sede de São Paulo de Olivença. Tive a oportunidade de visitar sua comunidade em dois momentos (jan. e abr. 2017).

Eronilde é cacique geral do povo Kambeba do Alto Solimões. Ela foi colega de turma de Prudêncio no curso de Licenciatura Intercultural Indígena ofertado pela UEA. Nasceu na sede do município de São Paulo de Olivença em uma área que não é reconhecida oficialmente como terra indígena. Conheci Eronilde numa atividade realizada durante a disciplina de Didática Intercultural (fev. 2016). Ela tem lutado pelo reconhecimento da terra indígena do povo Kambeba e vem enfrentando ameaças por conta da sua atuação política. Eronilde foi coordenadora das escolas Kambeba do município de São Paulo de Olivença até o ano de 2016. Em 2017, foi homenageada pela Associação Nacional de Pós-Graduação e Pesquisa em Educação (ANPEd) com o prêmio Nilton Bueno Fischer de Educação e Direitos Humanos, por sua luta. Atualmente, ela cursa o Mestrado em Linguística e Línguas Indígenas ofertado pelo Museu Nacional da Universidade Federal do Rio de Janeiro.

Eu e Eronilde mantemos contato constante via telefone e pelas redes sociais. Como ela vive na sede do município de São Paulo de Olivença, é mais fácil o contato. Já com Prudêncio e Ondino, que vivem em comunidade, fica mais difícil manter o contato. Com Prudêncio ainda consigo trocar mensagens por aplicativo no celular com mais frequência. Já com Ondino, só consegui encontrar e conversar presencialmente, durante o curso que ele fazia na sede da cidade.

A escolha desses interlocutores não foi mero acaso. São pessoas de experiências, formações e etnias diferentes, o que entendi ser enriquecedor para a pesquisa. Além disso, são lideranças reconhecidas em suas comunidades e, embora possam ser identificados, num primeiro momento,

Atalaia do Norte há uma turma com 35 indígenas de quatro etnias diferentes (Marubo, Matsés e Tüküna e Matis). Esses cursos são mantidos com recursos da UEA, do Programa Nacional de Formação de Professores do Governo Federal (PARFOR) e dos municípios em que são realizados. Esses não são os primeiros cursos superiores ofertados para a formação de professores indígenas na região mencionada, mas são os primeiros cursos de Pedagogia Intercultural Indígena.

12 Optei por manter seus nomes originais por entender que a atuação desses indígenas na criação de políticaspráticas educacionais cotidianas não pode ser invisibilizada. Além disso, os indígenas estão cientes e autorizaram o uso de seus nomes. Os conhecimentos advindos dessa pesquisa são produzidos com esses atores sociais. Considero importante dar crédito a esses atores e a suas criações cotidianas. 
como "professores-leigos" já ensinaram muito e conhecem o ofício, o que nos incita a questionar a própria noção de "leigo", já que a identificação remete ao não reconhecimento dos saberes docentes não formais, bem como dos saberes indígenas, dos quais os três lançam mão em suas práticas docentes. Ou seja, dentro do que se tornou objetivo dessa pesquisa - desinvisibilizar os conhecimentos não formais, não ocidentais e sua presença nas culturas indígenas e nas práticas docentes de professores indígenas -, o termo precisa ser questionado.

Assim sendo, considero urgente e necessário desinvisibilizar essas trajetórias de vida e de formação de professores, que ocorrem por caminhos outros para além do que reconhecemos como "formação docente". São essas historiografias contra-hegemônicas que busco compreender e desinvisibilizar, desconstruindo, com isso, a própria noção de professor-leigo, que não cabe para o contexto de formação desses professores indígenas.

\section{APRENDENDO COM OS INDÍGENAS}

A experiência como docente em cursos de formação de professores na região do Alto Solimões revelou-me que muitos estudantes que frequentam esses cursos já são professores em suas comunidades, contratados pelo poder público local. Ou seja, aprendi com a minha experiência que essas políticaspráticas docentes e de formação são habitadas por múltiplos percursos e redes de conhecimentos, muito além dos cursos oficiais de formação. As muitas conversas com professores indígenas em diferentes cursos e momentos revelaram-me que esses são professores que, em sua ação cotidiana, extrapolam em muito os limites da formação que tiveram, inserindo em seus cotidianos elementos de suas trajetórias múltiplas, forjadas nosdoscom os cotidianos das escolas indígenas.

Gostaria de destacar outros interlocutores e momentos importantes que venho tendo na região e que me ajudam a compreender melhor a dinâmica dos povos indígenas da fronteira em questão. Penso de imediato nas conversas realizadas com o Sr. Bidis, um indígena Kambeba também morador de São Paulo de Olivença, mas que trabalha como curandeiro na região do Alto Solimões e do Vale do Javari. Também nas conversas semanais que mantive durante os anos de 2018 e 2019 com o Cabildo de Los Pueblos Indígenas Urbanos de Letícia (CAPIUL), durante as rodas de mambeo ${ }^{13}$ com lideranças indígenas de diferentes etnias e mais velhos e, ainda, na experiência recente (dez. 2019) com o povo tüküna do Vale do Javari, na construção do Projeto Político Pedagógico das Escolas Indígenas Tüküna.

Entendo que, dessa forma, posso contribuir para potencializar nosso entendimento sobre a pluralidade presente na criação curricular cotidiana (OLIVEIRA, 2012) e, especificamente, naquela produzida por esses interlocutores em diferentes espaçostempos de educação indígena. Além disso, posso contribuir para o desenvolvimento de compreensões possíveis dessas tessituras de políticaspráticas educacionais cotidianas envolvendo esses povos, suas culturas e conhecimentos, ao mesmo tempo em que me permite apreender parte da trajetória desses povos nos contatos com outros povos, os brancos, sobretudo, nas relações que estabelecem e como isso constitui suas histórias.

\footnotetext{
13 Para os indígenas colombianos, o mambe (produto extraído da folha de coca) é um produto natural sagrado e de muita importância. As rodas de mambeo são realizadas no CAPIUL duas vezes por semana, e nelas são trocados conhecimentos relevantes sobre questões cotidianas dos povos indígenas que vivem na região. Comecei a frequentar as rodas no ano de 2018 e tenho, desde então, aprendido também com esses indígenas. Considero este um importante espaçotempo de educação indígena.
} 
Busco, de alguma forma, um meio de desinvisibilizar parte da "história que a História não conta" (como canta o samba da Estação Primeira de Mangueira de 2019), sobre processos de formação não oficiais. Assim, busco trazer para o debate reflexões sobre a tessitura de políticaspráticas cotidianas de criação curricular em diferentes espaçostempos de educação indígena. Entendo que essas ações nos trazem aprendizagens importantes para o campo da reflexão curricular, na medida em que permitem desvelar e revelar processos de tessitura curricular cotidiana. Esses processos partem do ponto de vista de seus praticantespensantes, inscrevendo, portanto, esse debate também em processo de reconhecimento da formação não oficial, de currículos como criação cotidiana dos indígenas que se faz em redes de conhecimentos, tecidas na vida cotidiana e na formação que a vida lhes proporcionou, valorizando os conhecimentos presentes nessa criação.

Parto aqui da convicção de que, no campo do currículo - entendido como inscrito num campo de reflexões políticas e epistemológicas mais amplas - é mais interessante e produtivo pensar em políticaspráticas educacionais cotidianas, tecidas em realidades complexas por praticantespensantes (OLIVEIRA, 2012) do currículo, do que em políticas em embate ou descoladas de práticas, como muitas vezes se supõe. Assim sendo, proponho o deslocamento das explicações a respeito do que "deveria existir" - numa perspectiva idealizante de políticas formuladas que seriam aplicadas em práticas - para a busca de compreensão daquilo que efetivamente existe na ação desses interlocutores, sobretudo quando pretendo abordar, a partir de conversas com alguns de seus protagonistas, diferentes aspectos da educação e da trajetória histórico-cultural indígena.

O termo políticaspráticas, em sua complexidade, me leva a considerar as redes de saberes, poderes e fazeres que se tecem nos cotidianos, e que os habitam, sempre articulando diferentes dimensões do real e das normas que lhes subjazem. Isso porque considero, com Oliveira (2013, p. 379), que:

As políticas educacionais, tanto em seus debates quanto nos textos que deles emergem, sempre respondem, de algum modo, às demandas das práticas, que por sua vez, se desenvolvem sempre por meio de um diálogo entre aquilo que advém dos textos e discursos oficiais - mas não por isso únicos - e as expectativas, desejos e possibilidades concretas dos sujeitos políticospraticantes. Nesse diálogo, posições e concepções diferenciadas a respeito do que é e deve ser a educação, o currículo, a sociedade e a prática educativa se expressam mais ou menos intensamente, em virtude do seu poder de intervenção sobre a produção das políticaspráticas curriculares, tanto em sua oficialidade textual quanto em sua realidade oficiosa. Ou seja, as políticas educacionais e as práticas cotidianas são produtos e produtoras de diálogos que as constituem e por elas são constituídos.

Essa complexidade característica dos processos de criação de políticaspráticas cotidianas impede, também, de se saber, nos processos sociais, quem é produto e quem é produtor. Nas palavras de Edgar Morin (1995, p. 182): "O processo social é um círculo produtivo ininterrupto no qual, de algum modo, os produtos são necessários à produção daquilo que os produz". Ou seja, há uma circularidade que não me permite definir onde começa e onde termina, só sei que estão permanentemente se realimentando, umas às outras.

$\mathrm{Na}$ conversa com Ondino, apesar do longo período sem concluir um curso de formação inicial, pude perceber que ele não desconsidera a importância dos cursos de formação para a sua prática, pelo contrário, valoriza os espaços de formação, tanto que vem participando de diferentes formações ao longo de sua trajetória. No entanto, por diferentes motivos, ele não conseguia 
concluir o curso. Ondino, por fim, concluiu o curso de Pedagogia Intercultural Indígena pela Universidade do Estado do Amazonas.

Interessante notar que, muitas vezes, na conversa com Ondino, ele relacionava o fato de ter o conhecimento indígena com aprendê-lo na escola, inscrevendo-se na compreensão ocidental moderna de que aprendemos por meio do ensino, e não pelas interações na / da vida cotidiana.

Leonardo: Você disse que você começou a estudar aos onze anos na comunidade. Estudou até a terceira série e veio para a sede fazer a quarta série, certo? Não era uma escola indígena. Era uma escola não indígena, né?

Ondino: Que nem o colégio que terminei a terceira.

Leonardo: Escola regular? Então você não tinha nenhum contato na escola com os conhecimentos indígenas. Ou tinha? Como que era isso? A relação...

Ondino: Não conhecia nenhum conhecimento indígena. Só depois, que teve o professor, um tal de João Pacheco. Também a mulher dele que dava aula para nós, parece que era Maria Vera o nome dela. Tivemos também a linguista, não sei se você conheceu: a Marilia.

Se entrou na escola aos onze anos, Ondino certamente chegou a ela com muitos conhecimentos indígenas, mas só passa a perceber esses conhecimentos quando alguém os traz, formalmente, a ele, quando um professor vem ensiná-los. O "tal Pacheco" é o professor João Pacheco de Oliveira, que fez pesquisa de campo por um longo período com os Ticuna na região do Alto Solimões.

$\mathrm{Na}$ narrativa de Ondino, a presença de João Pacheco e de outros pesquisadores e indigenistas revela o papel de destaque que eles tiveram para uma mudança de concepção sobre as escolas indígenas e os conhecimentos criados em seus cotidianos. Ao dizer que "não conhecia nenhum conhecimento indígena", Ondino reconhece que esses conhecimentos não eram valorizados nos cotidianos das escolas que ele frequentava como estudante.

Pude perceber, ao longo da pesquisa, que o cenário atual das escolas indígenas na região é diferente, como observamos na narrativa de Prudêncio. Prudêncio aposta na escola como um espaçotempo de revitalização da língua e cultura Kokama. Vale ressaltar que há uma diferença entre os povos Ticuna, Kokama e Kambeba na região. Os Ticuna têm a língua indígena como língua materna, enquanto os nascidos Kokama e Kambeba têm como língua materna o português.

Prudêncio: Hoje a gente vê que os nossos idosos não dominam mais a língua materna. Eles têm a cultura, produzem o artesanato, fazem a roça, plantam; então eles têm aquele hábito cultural, mas na parte da língua materna eles não têm o domínio. Então, a escola, a gente vê que é um espaço onde deve ser trabalhada a língua materna para nossos alunos e professores levarem para os nossos idosos o conhecimento da língua materna. Ao contrário dos Ticuna, que dominam a língua materna. Então, já vem de casa para a escola e na nossa está sendo invertido: da escola o conhecimento vai para a casa. Os alunos que aprendem aqui já levam o conhecimento para os pais. Às vezes eles dizem: "professor, papai não sabe o que é isso; a mamãe não sabe o que é isso". Então a gente fala: "explica para ele, vai colocando e vai ensinando". Ao invés dele te ensinar, você vai ensinar ele. Sobre a pergunta que o senhor fez, eu digo: a escola é um espaço muito importante para se trabalhar a língua materna. Está sendo muito... muito importante.

Quando Prudêncio narra que a escola está servindo como espaçotempo de revitalização da língua e da cultura Kokama, ele evidencia a importância de realizar pesquisas nosdoscom os cotidianos escolares. "[...] na nossa está sendo invertido: da escola o conhecimento para a casa. Os alunos que 
aprendem aqui já levam o conhecimento para os pais". Os usos que os Kokama fazem da escola "desobedecem a lei do lugar" (CERTEAU, 2012, p. 87) e tecem uma outra história da relação escola-comunidades indígenas. Ou seja, a fala de Prudêncio ajuda a reafirmar que a escola é produzida no fazer cotidiano dos praticantespensantes. É vã qualquer tentativa de se definir os sentidos das escolas que não seja através de suas práticas cotidianas, dos seus "usos" (CERTEAU, 2012).

A fala de Prudêncio marca uma distinção fundamental para se compreender a diferença da função social de uma escola indígena em um contexto de revitalização cultural e linguística, para a função social de uma escola indígena em um contexto em que a comunidade tem a língua indígena como língua materna e sua cultura "viva". Para muitas pessoas, o uso da língua é um fator determinante para diferenciar o indígena do não indígena, no entanto, há que se considerar a história de cada povo para que se perceba quais as condições de possibilidade de sustentar a sua língua em um contexto marcado por preconceito, discriminação, subalternização e silenciamento.

O CAPIUL, em Letícia (Colômbia), tem me ensinado muito sobre a forma de organização dos indígenas colombianos. Como disse anteriormente, esta organização reúne diferentes indígenas de diferentes etnias. Existem duas lideranças máximas: o governador, que é uma liderança política e quem dialoga prioritariamente com os poderes executivo e legislativo, em nível local e nacional; e existe o chefe da maloca, que é a autoridade máxima e o líder espiritual. O trabalho desenvolvido por esses indígenas é sempre decidido coletivamente pelos indígenas presentes, respeitando principalmente a sabedoria e a fala dos mais velhos. Para os indígenas da Amazônia colombiana, a existência da maloca é fundamental para a organização e sobrevivência do povo. A maloca é também considerada "a grande casa do conhecimento". Nela, são realizados reuniões, discussões e festejos.

O CAPIUL tem parceria também com a Universidade Nacional da Colômbia em Letícia (UNAL), e nessa relação existe constante troca de conhecimentos entre universidade e os indígenas do CAPIUL, via grupos de pesquisa e programa de pós-graduação. Nas conversas realizadas com o CAPIUL, em diferentes momentos, pude perceber que eles reconhecem a importância que a Universidade tem para a formação da população local sendo, assim, uma importante interlocutora para que os conhecimentos indígenas possam ecoar em diferentes contextos, não se reduzindo aos seus próprios grupos étnicos.

Além disso, o CAPIUL desenvolve projetos de prevenção de conflitos em regiões que sofrem impactos de pesca, caça indevida ou até mesmo garimpo. Esse é um problema que atinge os povos indígenas amazônicos de diferentes países, além da constante expansão do narcotráfico.

Outro projeto que pude presenciar e do qual pude participar com o CAPIUL foi a realização de um curso de línguas, em que, a cada semana, indígenas de uma etnia ensinavam um pouco do seu idioma para os demais parentes $^{14}$ da etnia, que não conheciam o idioma da sua própria etnia, mas também aos parentes de outra etnia que gostariam de aprender um pouco de outro idioma. O curso também foi aberto para não indígenas que participavam do CAPIUL.

Fiz alguns registros fotográficos em um dia de curso de que participei.

\footnotetext{
${ }^{14}$ A noção de parente para os indígenas não é uma questão de parentesco familiar, mas uma forma de reconhecimento de si e do outro como indígena.
} 

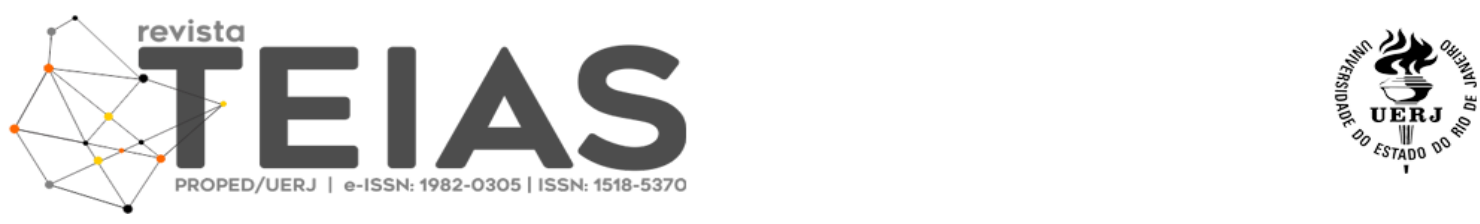

DOI: https://doi.org/10.12957/teias.2020.49706

Figura 5. Curso de línguas indígenas CAPIUL

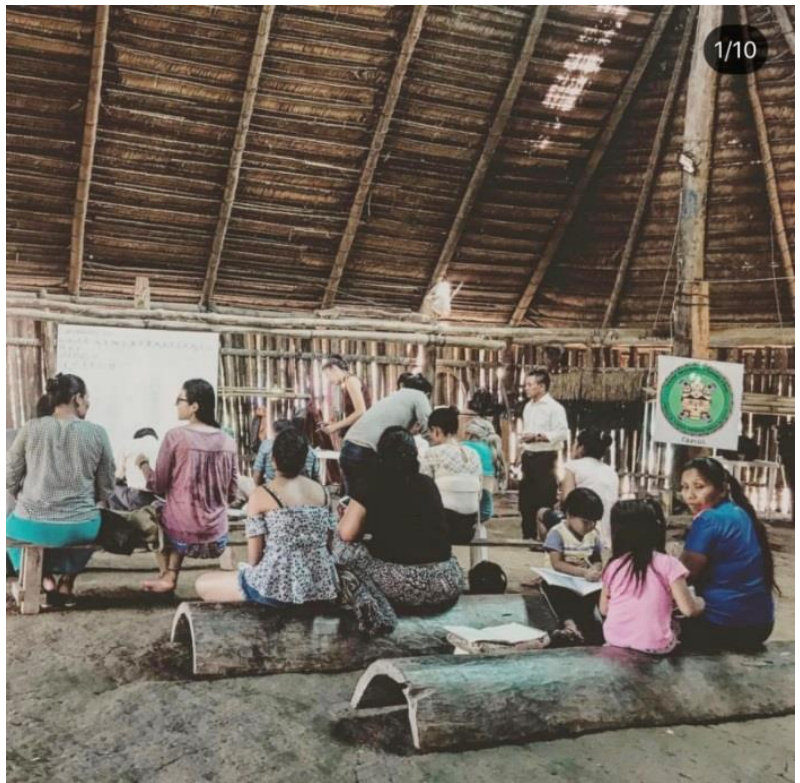

Fonte: Acervo do pesquisador. Em 10 nov. 2018.

Nessa primeira imagem (Figura 5), quis registrar as diferentes faixas etárias de pessoas que estavam participando e também as múltiplas conversas que foram ocorrendo ao longo da formação. Apesar da disposição de bancas e de uma lousa, tal como é possível observar nas salas de aula mais tradicionais, em nenhum momento as conversas foram cerceadas. Todos falavam e podiam falar a qualquer momento e a forma como falavam era normalmente muito calma e respeitosa.

A segunda imagem (Figura 6) é um momento em que o professor está ensinando o alfabeto em sua língua, mostrando a existência de outras vogais e consoantes, nesse caso, diferentes dos alfabetos espanhol e português.

\section{Figura 6: Professor ensinando o alfabeto e as vogais}

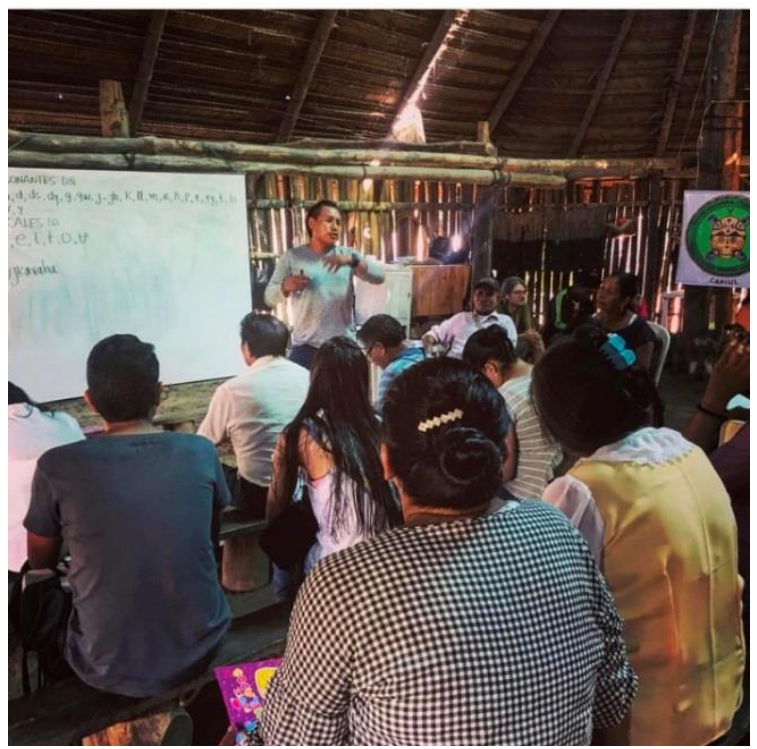

Fonte: Acervo do pesquisador. Em 10 nov. 2018. 
A terceira imagem (Figura 7) foi um registro que fiz de uma senhora mais velha falante do idioma, ensinando a pronúncia à parente de outra etnia. É importante ressaltar que, quando se trata de conhecimento indígena, seja ele sobre a língua, a história ou a cultura, o conhecimento dos mais velhos tem muita relevância. A eles é dado o poder de contradizer o conhecimento que algum outro indígena esteja transmitindo e eles não concordem. E é muito comum ver a existência de diálogo entre os mais velhos como troca de conhecimentos, em que normalmente um vai complementando o conhecimento narrado pelo outro.

Figura 7: Senhoras aprendendoensinando

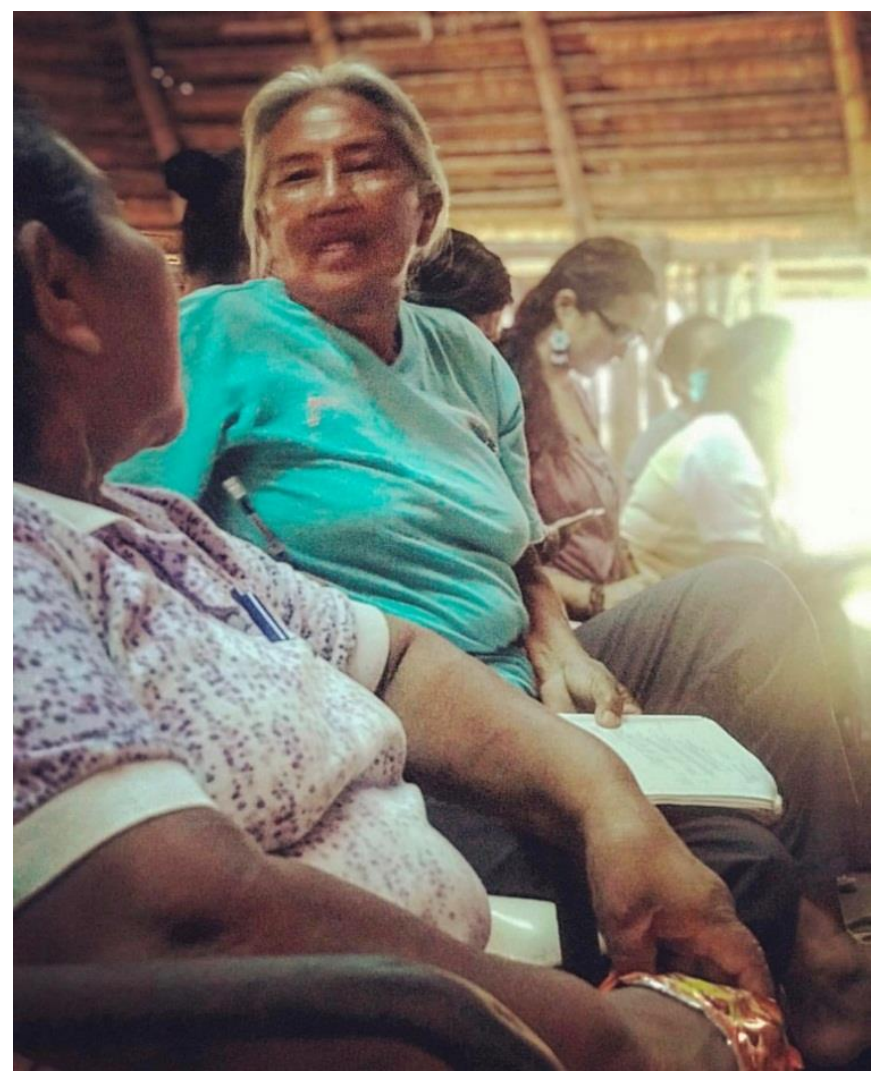

Fonte: Acervo do pesquisador. Em 10 nov. 2018.

\section{APRENDENDO A SER PARENTE}

A vivência e a troca de conhecimentos com os indígenas do CAPIUL ao longo dos últimos anos têm enriquecido demais a minha vida e a minha prática como professor nas disciplinas que tenho ministrado na Universidade. Temos tentado realizar algumas parcerias, com o apoio de outros professores e grupos de pesquisa do Centro de Estudos Superiores de Tabatinga e conseguimos realizar um importante evento em nossa unidade no final de 2018, organizado pelo Núcleo de Estudos Socioambientais da Amazônia (NESAM). Esperamos que outros eventos possam dar sequência a esse primeiro.

Certa vez, em uma das conversas na roda de mambeo, os indígenas disseram que eu já era do CAPIUL. Fiquei muito feliz e honrado com esse reconhecimento e imediatamente comecei a refletir sobre a questão que tento explicar a seguir. 
Ao longo da história, percebemos nitidamente que muitos indígenas e negros foram obrigados pelos colonizadores a esquecer sua cultura, sua história e seus conhecimentos. $\mathrm{Na}$ narrativa dos indígenas é muito comum, ainda hoje, ouvirmos a expressão "civilizar". Em nenhum momento desconsidero os movimentos de resistências, até porque este é um dos pressupostos importantes dessa pesquisa, mas tornar-se branco, deixar de ser índio, foi uma realidade, se não para os próprios indígenas que sofreram diretamente com esse processo civilizatório violento, para muitos de seus descendentes, que iam se distanciando cada vez mais da história e da cultura de seu povo. Por isso, vivemos hoje importantes movimentos de revitalização de identidades, línguas e culturas, em busca da história própria, narrada e tecida a partir dos povos indígenas, e que subjaz às práticas educativas, aos modos de lidar com o mundo, de conhecê-lo, de habitá-lo. Podemos então dizer que se aprende a ser branco. E foi assim que boa parte de nós fomos educados, não apenas nas escolas, mas em nossas vidas, quando fomos aprendendo a História ao mesmo tempo em que éramos dela excluídos. Foi então que a fala dos indígenas do CAPIUL me fez pensar em uma questão: se pode o indígena aprender a ser branco, pode o branco aprender a ser indígena?

Aprender a ser indígena não significa tornar-se indígena, algo que não depende única e exclusivamente de uma vontade pessoal, mas da convivência com os indígenas fez saltar aos meus olhos um topos interessante. É comum que os indígenas na Amazônia, de diferentes etnias, reconheçam-se como parente. E assim eles se chamam uns aos outros: "o parente marubo"; "o parente ticuna", "o parente matsés", e por aí vai. Na Universidade Popular dos Movimentos Sociais, realizada em 2019 durante a 39a Reunião Anual da ANPEd, a cacique kambeba Eronilde Fermin explicou que ser parente não significa necessariamente ser da mesma família, mas sim compartilhar a mesma luta, a mesma dor, e convidou a todos para nos tornarmos parentes. E é isso que venho aprendendo ao longo dos anos como professor em constante formação na Amazônia: a descolonizar as formas de aprender-ensinar e a tornar-me parente. Venho aprendendo a aprender com os indígenas, o que não significa desaprender tudo o que sei, mas pluralizar as formas e as maneiras de compreender e viver no mundo.

\section{REFERÊNCIAS}

ALVES, Nilda. Redes educativas "dentrofora" das escolas, exemplificadas pela formação de professores. Simpósio: Currículo e cotidiano escolar. In: Encontro Nacional de Didática e Práticas de Ensino - Endipe, XVI. Anais... Belo Horizonte, 20 a 23 de abril de 2010.

ALVES, Nilda. Decifrando o pergaminho - o cotidiano das escolas nas lógicas das redes cotidianas. In: OLIVEIRA, Inês Barbosa de; ALVES, Nilda (orgs.). Pesquisa no/do cotidiano das escolas - sobre redes de saberes. Petrópolis: DP\&A, 2008a. p. 15-38.

ALVES, Nilda. Sobre movimentos das pesquisas nos / dos / com os cotidianos. In: OLIVEIRA, Inês Barbosa de; ALVES, Nilda (orgs.). Pesquisa nos / dos / com os cotidianos das escolas - sobre redes de saberes. Petrópolis: DP\&A, 2008b. p. 39-48.

ALVES, Nilda. Decifrando o pergaminho - o cotidiano das escolas nas lógicas das redes cotidianas. In: OLIVEIRA, Inês Barbosa de; ALVES, Nilda (orgs.). Pesquisa no / do cotidiano das escolas - sobre redes de saberes. Rio de Janeiro: DP\&A, 2001. p. 13-38.

CERTEAU, Michel de. A invenção do cotidiano: 1. Artes de fazer. 19. ed. Petrópolis: Vozes, 2012. MORIN, Edgar. El pensamiento complejo. Madrid: Gedisa, 1995.

OLIVEIRA, Inês Barbosa de. Currículo e processos de aprendizagemensino: políticaspráticas educacionais cotidianas. Currículo sem Fronteiras, v. 13, n. 3, p. 375-391, set. / dez. 2013. 
OLIVEIRA, Inês Barbosa de. O currículo como criação cotidiana. Petrópolis: DP\&A, 2012.

OLIVEIRA, Inês Barbosa de. Currículos praticados entre a invisibilidade e a legitimação: um percurso nosdoscom os cotidianos. In: FERRAÇO, Carlos Eduardo (org.). Currículo e educaşão básica: por entre redes de conhecimentos, imagens, narrativas, experiências e devires. Rio de Janeiro: Rovelle, 2011.

OLIVEIRA, Inês Barbosa de. Aprendizagens culturais cotidianas, cidadania e educação. In: OLIVEIRA, Inês Barbosa de; SGARBI, Paulo. Redes culturais, diversidade e educação. Petrópolis: DP\&A, 2002.

OLIVEIRA, Inês Barbosa de; PEIXOTO, Leonardo Ferreira. Memórias de formação e educação indígena: narrativas docentes e ecologia de saberes no cotidiano da educação indígena. In: SOUZA, Elizeu Clementino de; MONTEIRO, Filomena de Arruda; PASSEGGI, Maria da Conceição. Congresso Internacional de Pesquisa (Auto)biográfica, VII. Anais... CD-ROM - Cuiabá. BIOgraph, 2016.

OLIVEIRA, Jelson Roberto de. Nietzsche e o Heráclito que ri: solidão, alegria trágica e devir inocente. Veritas, v. 55, n. 3, p. 217-235, set. /dez. 2010.

SANTOS, Boaventura de Sousa. Pela mão de Alice: o social e o político na transição pós-moderna. São Paulo: Cortez, 1995.

Submetido em março de 2020.

Aprovado em abril de 2020.

\section{Informações do autor}

Leonardo Ferreira Peixoto

Professor do Centro de Estudos Superiores de Tabatinga da Universidade do Estado do Amazonas.

Líder do Grupo de Pesquisa Redes Indígenas: povos indígenas e redes educativas.

E-mail:1peixoto@uea.edu.br

ORCID: https://orcid.org/0000-0002-4817-1701

Link Lattes: http://lattes.cnpq.br/3006297256905004 